\title{
VIDEO AND IMAGE SYSTEMS ENGINEERING EDUCATION FOR THE 21ST CENTURY *
}

\author{
J. P. Allebach ${ }^{\dagger}$, C. A. Bouman ${ }^{\dagger}$, E. J. Coyle ${ }^{\dagger}$, E. J. Delp ${ }^{\dagger}$, D. A. Landgrebe ${ }^{\dagger}$ \\ A. A. Maciejewski ${ }^{\dagger}$, Z. Pizlo ${ }^{\ddagger}$, N. B. Shroff $f^{\dagger}$ M. D. Zoltowski ${ }^{\dagger}$ \\ †School of Electrical and Computer Engineering, Purdue University \\ West Lafayette, IN 47907-1285 \\ $\ddagger$ Department of Psychological Sciences, Purdue University \\ West Lafayette, IN 47907-1364
}

\begin{abstract}
We are developing a new graduate program at Purdue in Video and Image Systems Engineering (VISE). The project is comprised of three parts: a new curriculum centered around a degree option in VISE to be earned as part of the Masters or Ph.D. degrees; a state-of-theart lecture/laboratory facility for instruction, laboratory experiments, and project and homework activities in VISE courses; and enhancement of existing courses and development of new courses in the VISE area.
\end{abstract}

\section{Introduction}

Imaging in the School of Electrical and Computer Engineering (ECE) of Purdue University dates back to 1931 when Roscoe George and Howard J. Heim invented the first electronic television receiver which is now on exhibit at the Museum of Broadcast Communications in Chicago, IL [1]. From these beginnings, imaging has grown to become a major educational and research component of the ECE program. There are presently 14 ECE faculty conducting research related to imaging. At the graduate level, there are presently 13 courses in the imaging area that have either permanent status, or which are under development at this time. At the undergraduate level, we have a "capstone" Senior ECE course in digital signal processing [2] which has a strong imaging component.

Building on this solid base, we have initiated a threepronged strategy that will move our imaging program forward by a major step, and prepare us to enter the 21st century in video and imaging. The VISE curriculum option will unify and focus attention on this area of ECE. After completing a prescribed set of courses,

\footnotetext{
"Supported by an Image Systems Engineering Grant from Hewlett-Packard Company.
}

including required and elective courses from the VISE group, students will receive a certificate and appropriate notation on their transcript. The program will include a special seminar series featuring speakers from industry and academia in the VISE area. The option will be structured in such a way as to allow access by students who are not ECE majors.

At the end of the third year of the project, the VISE facility will include 31 video and graphics workstations, 2 file servers, a media server with optical disk jukebox, a digital video disk recorder, and a complement of printers and scanners. A 64 port ATM switch will provide high-speed connectivity to existing resources within ECE and beyond. This network will support transmission of multiple streams of real-time digital video. The facility will be configured to enable use as a lecture room for highly interactive and visually enhanced learning, a laboratory for providing the student with a wide range of hands-on learning experiences, and a resource for unscheduled independent work on assignments and projects.

With the new capabilities offered by the VISE facility, we will be able to embark on a new direction in video and imaging education - a direction that will look beyond traditional imaging to the complete digital imaging system. This new approach will synergistically combine the study of video, images, graphics, networking and perception, thereby preparing our students for employment in today's increasingly competitive and fast-moving workplace.

\section{VISE Degree Option}

We are planning to introduce both Masters and Ph.D. level degree options in Video and Image Systems Engineering. The VISE degree option will be earned as part of a regular Masters or Ph.D. degree. For the 
VISE degree option, students will chose one of the following areas of specialization: Imaging and Video, Remote Sensing, Graphics, Networks, and Psychology. In addition to whatever conditions must be satisfied to receive their Masters or Ph.D. degree, students must complete the following requirements to fulfill the VISE degree option:

A. 4 courses (12 credits) from the VISE list

B. 3 of these courses ( 9 credits) must be VISE primary courses

C. 2 of the VISE primary courses must be from the students area of specialization

These requirements work together to assure that the student's plan of study will have depth in the student's area of specialization, while allowing for some breadth outside this area. The VISE primary courses are shown in Table 1, grouped according to level and area of specialization. The VISE secondary courses are also listed in Table 1. These courses provide background and breadth relative to the topics covered in the VISE primary courses. In addition, if the degree requires a thesis, the thesis must address a topic from the VISE area.

The VISE degree option will be administered by a VISE steering committee. The committee will be responsible for determining which courses will be included under the VISE umbrella, for setting requirements for the VISE degree option, and for setting policy regarding configuration and use of the VISE facility. This structure incoporates mechanisms for allowing the degree option to evolve. Specifically; it is expected that as the option becomes established, additional courses will be added to the VISE group and additional academic units will become involved.

\section{State-of-the-Art Facility}

The VISE facility will have state-of-the-art functionality both as a laboratory and a lecture facility. The diagram of Fig. 1 shows that the equipment will be arranged so that the instructor can lecture from a podium area equipped with a rear projection system, a high speed graphics workstation, and a traditional blackboard. At the heart of the facility will be 31 high-performance workstations, 16 graphics workstations and 15 video workstations. (During the first year, we will obtain 7 graphics and 9 video workstations.) The graphics workstations are C110 machines equipped with Visualize 48 graphics. The double buffered 24bit graphics with $Z$ buffer and texture mapping will

\begin{tabular}{|c|c|}
\hline & Primary Courses \\
\hline $\begin{array}{l}\text { Under- } \\
\text { graduate }\end{array}$ & $\begin{array}{l}\text { EE } 438 \text { Digital Signal Processing with } \\
\text { Applications }\end{array}$ \\
\hline $\begin{array}{r}\text { Imaging } \\
\& \text { Video } \\
\text { (New) } \\
\text { (New) } \\
\text { (New) }\end{array}$ & $\begin{array}{l}\text { EE } 637 \text { Digital Image Processing I } \\
\text { EE } 641 \text { Digital Image Processing II } \\
\text { EE } 6 \text { XX An Introduction to Digital Video Sig- } \\
\text { nals and Systems } \\
\text { EE } 6 \text { XX Introduction to Biomedical Imaging } \\
\text { Systems } \\
\text { EE } 6 \text { XX Principles of Color Imaging Systems }\end{array}$ \\
\hline $\begin{array}{l}\text { Remote } \\
\text { Sensing }\end{array}$ & EE 577 Engineering Aspects of Remote Sensing \\
\hline $\begin{array}{c}\text { Graphics } \\
\text { (New) }\end{array}$ & $\begin{array}{l}\text { EE } 5 X X \text { Image Synthesis } \\
\text { EE } 628 \text { Computer Graphic Simulation and } \\
\text { Visualization }\end{array}$ \\
\hline Networks & $\begin{array}{l}\text { EE } 547 \text { Introduction to Computer Communi- } \\
\text { cation Networks } \\
\text { EE } 647 \text { Performance Modeling of Computer } \\
\text { Communication Networks }\end{array}$ \\
\hline $\begin{array}{l}\text { Psycho- } \\
\operatorname{logy}\end{array}$ & $\begin{array}{l}\text { PSY } 606 \text { Special Topics in Quantitative } \\
\text { Psychology } \\
\text { PSY } 628 \text { Perceptual Processes } \\
\text { PSY } 637 \text { Human Information Processing }\end{array}$ \\
\hline
\end{tabular}

\begin{tabular}{|c|c|}
\hline \multicolumn{2}{|r|}{ Secondary Courses } \\
\hline $\begin{array}{l}\text { Under- } \\
\text { graduate }\end{array}$ & EE 440 Transmission of Information \\
\hline Graduate & $\begin{array}{l}\text { EE } 565 \text { Computer Architecture } \\
\text { EE } 627 \text { Introduction to Cryptography and Se- } \\
\text { cure Communication } \\
\text { EE } 629 \text { Introduction to Neural Networks } \\
\text { EE } 638 \text { Digital Signal Processing I } \\
\text { EE } 639 \text { Error Control Coding } \\
\text { EE } 642 \text { Information Theory and Source Coding } \\
\text { EE } 645 \text { Estimation Theory } \\
\text { EE } 648 \text { Digital Signal Processing II } \\
\text { EE } 661 \text { Computer Vision } \\
\text { EE } 662 \text { Pattern Recognition and Decision Mak- } \\
\text { ing Processes } \\
\text { IE } 577 \text { Human Factors in Engineering } \\
\text { ME } 573 \text { Interactive Computer Graphics } \\
\text { PSY } 514 \text { Introduction to Mathematical } \\
\text { Psychology } \\
\text { PSY } 518 \text { Memory and Cognition } \\
\text { PSY } 624 \text { Human Learning and Memory } \\
\text { PSY } 607 \text { Scaling and Measurement }\end{array}$ \\
\hline
\end{tabular}

Table 1: VISE primary and secondary courses. Primary courses focus on video, images, and networking; and will utilize the VISE lecture/laboratory facility. Secondary courses have an image systems engineering component and also provide foundation material for primary courses. 
Video and Image Systems Engineering Facility



Figure 1: Layout of VISE lecture/laboratory facility. The facility will ultimately contain 31 workstations with 14 of the workstations obtained during the first year. High speed real time networking, and high performance graphics and video will facilitate a 21st century educational experience.

allow the students to perform experiments using realtime graphics simulation. The video workstations will have 24-bit color displays with Visualize 24 graphics. All workstations will be capable of decoding real-time MPEG video using the MPower software package.

In order to support real-time video distribution and the manipulation of large data sets, the lab will be equipped with a $155 \mathrm{Mbps}$ Asynchronous Transfer Mode (ATM) network as shown in Fig. 2. This network will also provide high speed connectivity to a wide range of research and teaching resources ranging from the MasPar MP-1 supercomputer to the 1,000 workstations and internet access of the Engineering Computer Network.

In the first year, the laboratory will be equipped with a variety of special purpose imaging devices such as color printers and color scanners. In years two and three, a digital media server will be added along with mass storage in the form of an optical jukebox, a hard disk array, and a digital video disk recorder. This combination of media server and mass storage will allow educational material to be distributed on computer networks at Purdue. The facility will also serve as a testbed for studying digital video distribution technology.

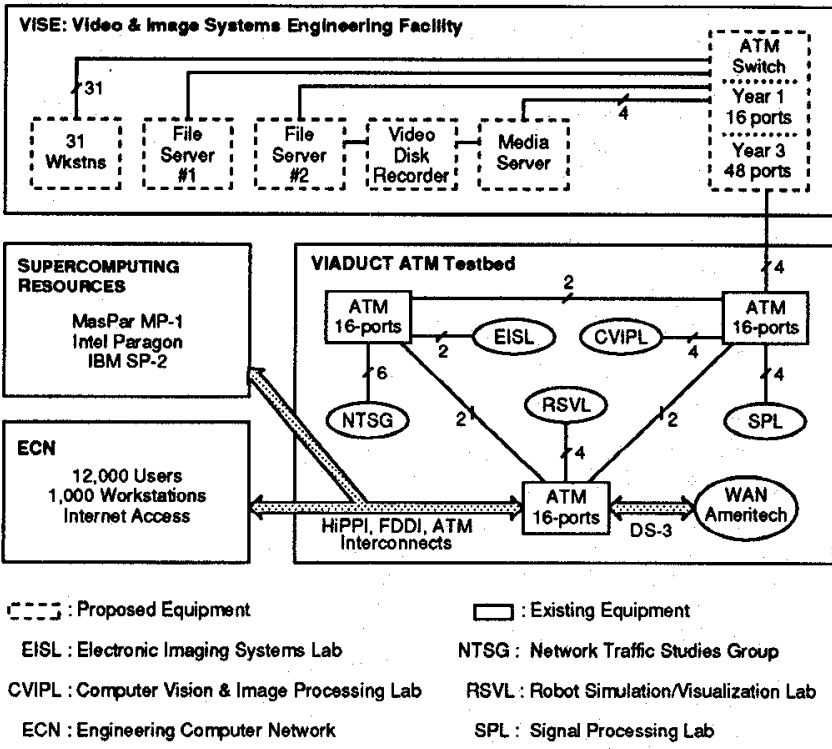

Figure 2: Diagram of the network connectivity that will be available to VISE users.

\section{Course Enhancement and De- velopment}

The new VISE facility will support a range of uses by the primary courses. It will be scheduled for both lecture and laboratory use. When not scheduled, the facility will be available for use by students on a drop-in basis to work on homework assignments and projects. Once the full complement of 31 workstations becomes available, the facility will enable us to experiment with novel approaches to instruction. With one or two students at each workstation, we will be able to move away from the traditional passive and largely uni-directional lecture format toward a much more interactive mode of learning. Discovering how to effectively utilize this medium will be a significant challenge; but the potential pay-off is great. In the rest of this section, we highlight some of the most important new uses envisioned for the facility.

Students in EE 577 Engineering Aspects of Remote Sensing will use the facility to develop methods to visualize high dimensional spectral response distributions of designated ground cover classes. EE $6 X X$ An Introduction to Biomedical Imaging Systems will use the facility for high performance computation, graphics rendering, and video. For example, cardiac ultrasound can be used to assess cardiac wall motion problems by acquiring a series of images and playing them as video to observe a beating heart. The video disk and workstations in VISE will be used by the students to observe, process, 

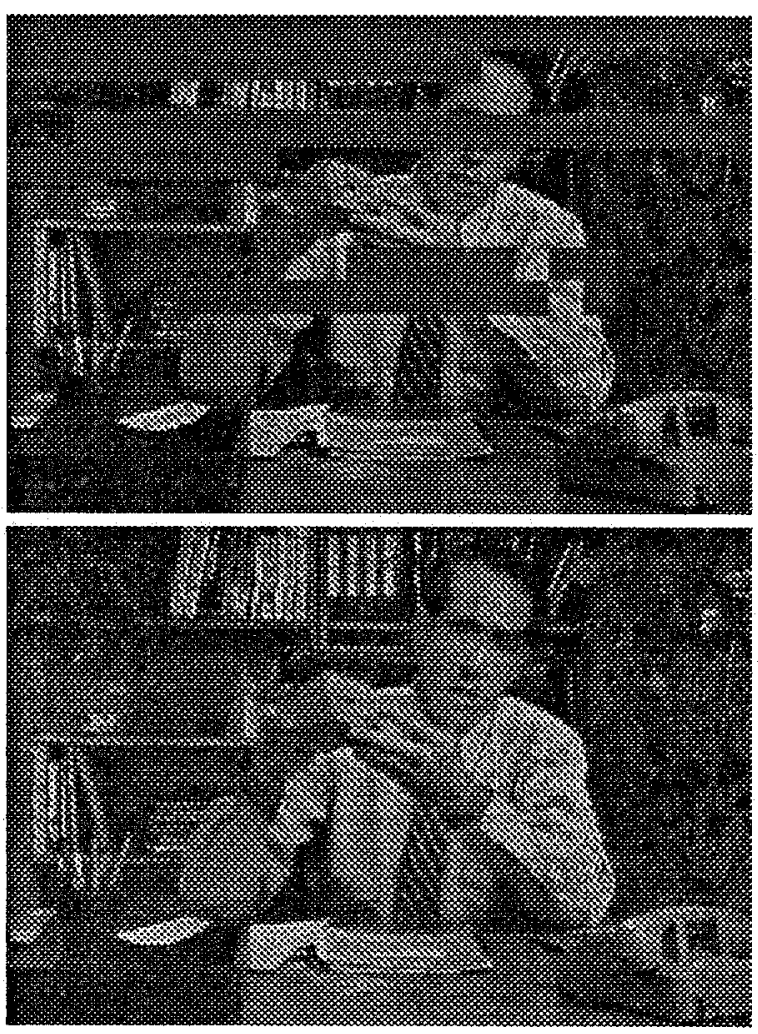

Figure 3: Effect of lost ATM cells (top) and motioncompensated reconstruction from adjacent frames (bottom).

and analyze such cardiac video sequences.

Students in EE $6 X X$ An Introduction to Digital Video Signals and Systems will be able to work directly with video sequence data in both compressed and uncompressed formats to demonstrate JPEG, MPEG-1 and MPEG-2 video compression standards, as well as low bit rate approaches such as H.261 and MPEG-4. They will be able to examine such issues as error concealment illustrated in Fig. 3. The ATM network and media server will provide realistic platforms to study real-time video distribution methods. The special purpose color display and printing equipment in the VISE facility will be essential to EE $6 X X$ Principles of Color Imaging Systems. Calibrated 24-bit color displays will allow students to perform psychophysical experiments in colorimetry, color constancy, and color appearance. In addition, the facility will support student projects in color halftoning, device calibration, and color printer modeling.

For EE $5 X X$ Image Synthesis, we will be able to implement and demonstrate a wider range of techniques for producing synthetic images including ray tracing, radiosity, and hardware supported texture mapping. In

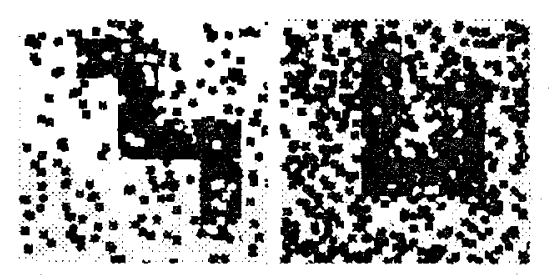

Figure 4: Stimuli for an experiment to demonstrate how humans detect objects in the presence of clutter.

EE 628 Computer Graphic Simulation and Visualization, we will be able to provide more accurate simulation of motion in synthetic video sequences.

The VISE facility will have a significant impact on our courses in computer networks $E E$ 547 and $E E$ 647. It will be an excellent source of both video and still image traffic for case studies showing the impact of network design decisions on the quality of the irnages and video delivered across the network. Of particular interest will be classroom demonstrations of the interactions between the following traffic types: real-time video and still-image traffic from the VISE facility; realtime control traffic from the RSVL lab; and large volume data traffic from supercomputing and other applications. These traffic sources will be tied together by our NSF-funded ATM network testbed shown in Fig. 2.

For PSY 606 Special Topics in Quantitative Psychology and PSY 628 Perceptual Processes, the VISE facility will allow students to study psychophysical phenomena by designing perceptual experiments, choosing stimuli and serving as subjects. For example, short experiments will be used to demonstrate perceptual phenomena and/or psychophysical methods. These include brightness matching using the method of adjustment, shape constancy using the method of limits, and object detection using the signal detection method. Figure 4 illustrates the type of stimuli that might be used in an object detection experiment.

\section{References}

[1] L. A. Geddes, A Century of Progress: The History of Electrical Engineering at Purdue (1888-1988) School of Electrical Engineering, Purdue University, West Lafayette, IN (1988).

[2] M. D. Zoltowski, J. P. Allebach, and C. A. Bouman, "Digital Signal Processing with Applications: A New and Successful Approach to Undergraduate DSP Education," IEEE Trans. on Education., Special Issue on Digital Signal Processing Undergraduate Education, Vol. 39, pp. 120-126, May 1996. 